\title{
Glycemic control among type 2 diabetic patients attending the Family Medicine Health Center and the Diabetic Health Center in Erbil, Iraq: a comparative study
}

\section{Ali Shakir Dauod*}

\section{Abstract}

Background and objective: Type 2 diabetes mellitus constitutes a universal growing community health problem particularly in developing countries. This study aimed to determine and compare the rate of the glycemic control and other biochemical parameters of type 2 diabetic patients treated in a primary health center and the diabetic center.

Methods: A cross-sectional study was carried out on a sample of 300 adult patient's aged $\geq 18$ years with type 2 diabetes who attended Brayati family medicine center and the diabetic center in Erbil city during the period from the $1^{\text {st }}$ of January 2015 to the 28th of February 2016.
\end{abstract}

Results: The mean hemoglobin A1c among patients of the diabetes center was significantly higher than that among patients of the Brayati center $(8.28 \%$ and $7.21 \%$, respectively) $(P<0.001)$ and the means of triglycerides, total cholesterol, and LDL were significantly higher among patients of the diabetes center compared with Brayati center $(P<0.001)$. Half of the patients at Brayati center had controlled diabetes compared with only $24.7 \%$ of patients at the diabetes center $(P<0.001)$, and $50 \%$ of the Brayati center sample had equal or more than three controlled risk factors compared with only one-quarter of the diabetes center sample $(P<0.001)$. Logistic regression analysis showed that being a patient in Brayati center (compared with diabetes center) $(P<0.001$; OR $=$ $3.1)$, diabetes duration of less than five years $(P<0.001$; OR $=3)$, and controlled lipid profile $(P=0.004$; OR $=2.5)$ were significantly associated with diabetes control.

Conclusion: Type 2 diabetes can be effectively managed at primary health care, and good glycemic control can be achieved by a greater effort of the health care providers. Reorganizing primary care practice and shifting toward family medicine practice is necessary.

Keywords: Type 2 diabetes mellitus; Primary health care; Family medicine; Diabetes center; Glycemic control.

\section{Introduction}

Type 2 diabetes mellitus (T2DM) is one of the most common chronic illnesses in adults. The high levels of morbidity and mortality due to diabetes create an increasing health problem worldwide. It is predictable that the number of diabetic patients will rise from 386.7 to 591.9 million by the next twenty years. ${ }^{1,2}$ The preservation of near normal blood glucose levels is central to the prevention of the macro-vascular complications of diabetes, diabetic retinopathy, diabetic renal disease, and diabetic neuropathy. ${ }^{3,4}$ For diabetes, they should have a Hemoglobin A1c $(\mathrm{HbA} 1 \mathrm{c})$ test at least twice a year to determine their long-term blood glucose control. The test measures the average blood glucose during the previous 2-3 months. For those without diabetes, the normal $\mathrm{HbA} 1 \mathrm{c}$ range is $4-6 \%$ whereas for those with diabetes, the lower the $\mathrm{HbA1c}$ value, the better the diabetes control and the lower the risk of developing complications. Glycemic control goal is achieved when the $\mathrm{HbA} 1 \mathrm{c}$ value is less than $7 \%$. That may be a tough target to hit, but it is important to try because of the

* Department of Community Medicine, College of Medicine, Hawler Medical University, Erbil, Iraq. 
lower the $\mathrm{HbA} 1 \mathrm{c}$, the lower the health risk. Since primary care is the essential base in effective health care systems, the majority of diabetic patients are managed in primary care setting. ${ }^{5-8}$ Previous studies in developed nations proved that the standard of care for diabetes in primary health care (PHC) could be as good as secondary care ${ }^{9,10}$ Re-arranging primary care practice had been strongly recommended by future of family medicine report. ${ }^{10}$ However, there is still a lack of studies in the literature in the developing countries intended to assess the effectiveness of care of diabetic patients who are cared by PHC physicians compared to those who are cared by the diabetic center or hospital physicians. Hence, this study aimed to determine the rate of glycemic control and lipids profile in patients with T2DM attending one of the family medicine health centers compared with a specialized diabetic center in Erbil city.

\section{Methods}

A cross-sectional study was carried out in Brayati family medicine center and Leila Qasim diabetic center in Erbil city of Iraq between $1^{\text {st }}$ of January 2015 to the $28^{\text {th }}$ of February 2016. The centers are opened daily (except for public holidays), from 8.00 am to $2.00 \mathrm{pm}$, and on average 50-100 patients are seen on a daily bases. The Brayati center is the first of the few family medicine centers in Erbil, and the clinics are run mainly by family physicians. The center is characterized by close follow-up of patients and continuity of care as the patient has to see the physician to take medicine on a monthly basis. The Leila Qasim health center for diabetes started to function officially in Erbil on ${ }^{1 \text { st }}$ of December 2007, and the clinics run mainly by an internist and full-time nurses. The majority of diabetic patients that attend this center are referred from primary health centers, hospitals and some are referred by private clinics. The sample size was calculated based on the estimated prevalence of diabetic patients in Iraq of $10.7 \%$ according to the International Diabetes Federation (IDF) of the Middle East and North Africa (MENA) $)^{1}$ and on the precision of $5 \%{ }^{11}$ This calculated sample size was approximately 146 patients for each group. Patients included in the study were T2DM patients' aged $\geq 18$ years and receiving ongoing diabetic treatment. To escape sampling bias, simple random samples of T2DM patients that attend clinics every three days are taken from both centers. All participants informed of the study objective and then recruited after providing verbal informed consent. A specially designed questionnaire was used to address all relevant patients' demographic characteristics, duration of diabetes, family history of diabetes, and smoking status. Height in centimeter $(\mathrm{cm})$, weight in kilogram $(\mathrm{kg})$, waist circumferences in $(\mathrm{cm})$, SBP and DBP in millimeter mercury $(\mathrm{mmHg})$ were measured by the researcher for all participants in standard fashion. After ending the interview, completing the questionnaire and physical examination, all participants were asked to provide a fasting blood sample in laboratory room under fully aseptic condition. Fasting blood glucose (FPG) in mg/dl, HbA1c \%, and fasting lipid profile in $\mathrm{mg} / \mathrm{dl}$ were measured. HbA1c analyzed using diasys one HbA1CFS (particle enhanced immunoturbidimetric test) which is a specific immunoassay for human $\mathrm{HbA} 1 \mathrm{c}$ in both centers. Data were analyzed using the statistical package for the social sciences (version 19). Chi-square test of association was used to compare between proportions. Student's t-test for two independent samples was used to compare means. Logistic regression analysis was used where the dependent variable was DM control. Variables found by conventional statistical analysis to be significantly associated with diabetes control were entered into the regression model. A $P$ value of $\leq 0.05$ was considered statistically significant. The socioeconomic status (SES) scoring that range from $0-12$ was calculated from educational level 
(0-5), home ownership (0-2), number of rooms (0-2), car ownership (0-1), and monthly family income (0-2). Scoring lower than 5 is considered as low SES, 5-8 is medium SES, and more than 8 is considered as high SES. Body mass index (BMI) was calculated by dividing weight in kilogram by squared height in meter and categorized as normal if $\mathrm{BMl}<25 \mathrm{~kg} / \mathrm{m}^{2}$, overweight between $25-30 \mathrm{~kg} / \mathrm{m}^{2}$ and obesity if $\mathrm{BMI} \geq 30 \mathrm{~kg} / \mathrm{m}^{2}$. Diabetes control is defined as $\mathrm{HbA} 1 \mathrm{c}<7 \%$, FPG level $<130$ $\mathrm{mg} / \mathrm{dL}$, total cholesterol (TC) $<200 \mathrm{mg} / \mathrm{dl}$, triglyceride $(\mathrm{TG})<150 \mathrm{mg} / \mathrm{dl}$, low density lipoprotein cholesterol (LDL-C) $<100 \mathrm{mg} / \mathrm{dl}$ and high density lipoprotein cholesterol $(\mathrm{HDL}-\mathrm{C}) \geq 40 \mathrm{mg} / \mathrm{dl}$. Microalbuminuria was considered positive if it was $\geq 30$ to 299 $\mathrm{mg} / \mathrm{L}$. The research ethics committee of the College of the Medicine at Hawler Medical University approved the study protocol, and a formal consent letter from Erbil Directorate of Health was obtained before starting the research.

\section{Results}

The total sample of the study was 300 diabetic patients, 150 were taken from the health care center. The mean age of patients of DM center was 56.73 years, while that of the Brayati center was 55.13 years $(P=0.177)$. The mean $\mathrm{HbA} 1 \mathrm{c}$ of patients of the DM center $(8.28 \%)$ was significantly higher than the mean $(7.21 \%)$ of patients of Brayati center $(P<0.001)$. The means of triglycerides, total cholesterol, and LDL were significantly higher in the DM center than Brayati. The mean BMI of the patients were significantly $(P=0.001)$ higher in the Brayati center (29.27) than the DM center (27.39). Details are showed in Table 1.

Table 1: Means of the studied numerical variables of patients of DM and Brayati centers.

\begin{tabular}{|c|c|c|c|c|c|}
\hline \multirow[t]{2}{*}{ Variables } & \multicolumn{2}{|c|}{$\begin{array}{l}\text { Leila Qasim diabetic } \\
\text { center }\end{array}$} & \multicolumn{2}{|c|}{$\begin{array}{l}\text { Brayati family medicine } \\
\text { center }\end{array}$} & \multirow{2}{*}{$P$ value } \\
\hline & Mean & SD & Mean & SD & \\
\hline Age & 56.73 & 9.75 & 55.13 & 10.70 & 0.177 \\
\hline HbA1c & 8.28 & 1.63 & 7.21 & 1.08 & $<0.001$ \\
\hline $\begin{array}{l}\text { Duration of diabetes in } \\
\text { month }\end{array}$ & 77.76 & 50.94 & 81.28 & 67.87 & 0.612 \\
\hline Triglyceride in $\mathrm{mg} / \mathrm{dl}$ & 194.62 & 77.29 & 154.71 & 73.38 & $<0.001$ \\
\hline Total cholesterol in $\mathrm{mg} / \mathrm{dl}$ & 222.60 & 52.21 & 196.07 & 46.42 & $<0.001$ \\
\hline LDL in mg/dl & 131.47 & 35.34 & 117.43 & 36.44 & 0.001 \\
\hline HDL in $\mathrm{mg} / \mathrm{dl}$ & 42.05 & 7.73 & 41.93 & 10.43 & 0.912 \\
\hline BMI & 27.39 & 3.26 & 29.27 & 5.71 & 0.001 \\
\hline
\end{tabular}

${ }^{*}$ By t-test of two independent samples. 
The proportion of patients who had the patients in the Brayati center had controlled DM, lipids, and BMI were significantly higher among Brayati center patients than DM center patients. Half of controlled diabetes, compared with $24.7 \%$ of patients in the DM center $(P<0.001)$ as shown in Table 2.

Table 2: Proportions of patients achieving the targets, in each of DM center and Brayati center.

\begin{tabular}{|c|c|c|c|c|c|}
\hline \multirow{2}{*}{ Target } & \multicolumn{2}{|c|}{$\begin{array}{l}\text { Leila Qasim diabetic } \\
\text { center }(n=150)\end{array}$} & \multicolumn{2}{|c|}{$\begin{array}{l}\text { Brayati family medicine } \\
\text { center }(n=150)\end{array}$} & \multirow{2}{*}{$P$ value } \\
\hline & No. & $\%$ & No. & $\%$ & \\
\hline Controlled DM & 37 & 24.7 & 75 & 50.0 & $<0.001$ \\
\hline Controlled FPG & 12 & 8.0 & 11 & 7.3 & 0.828 \\
\hline Controlled TC & 61 & 40.7 & 84 & 56.0 & 0.008 \\
\hline Controlled LDL & 23 & 15.3 & 45 & 30.0 & 0.002 \\
\hline Controlled TG & 42 & 28.0 & 61 & 40.7 & 0.021 \\
\hline Good HDL & 54 & 36.0 & 62 & 41.3 & 0.343 \\
\hline Controlled BP & 63 & 42.0 & 72 & 48.0 & 0.296 \\
\hline $\begin{array}{l}\text { No microalbu- } \\
\text { minurea }\end{array}$ & 93 & 62.0 & 93 & 62.0 & 1.000 \\
\hline Normal BMI & 32 & 21.3 & 40 & 26.7 & $<0.001$ \\
\hline
\end{tabular}

${ }^{*}$ By Chi square test. 
In each of the studied centers, there was no significant association between diabetes control with many variables like age, sex, SES, smoking, as well as family history of DM. The less the duration of diabetes the more the percentage of DM control irrespective of the center whether DM or Brayati centers. In the DM center,
$37.8 \%$ of those who practice exercise were controlled compared with $20.4 \%$ of those who don't practice exercise $(P=0.032)$, while in the Brayati center, no significant association $(P=0.344)$ was detected between physical activity and DM control $(P=0.344)$ as shown in Table 3.

Table 3: DM control by different factors in the two centers.

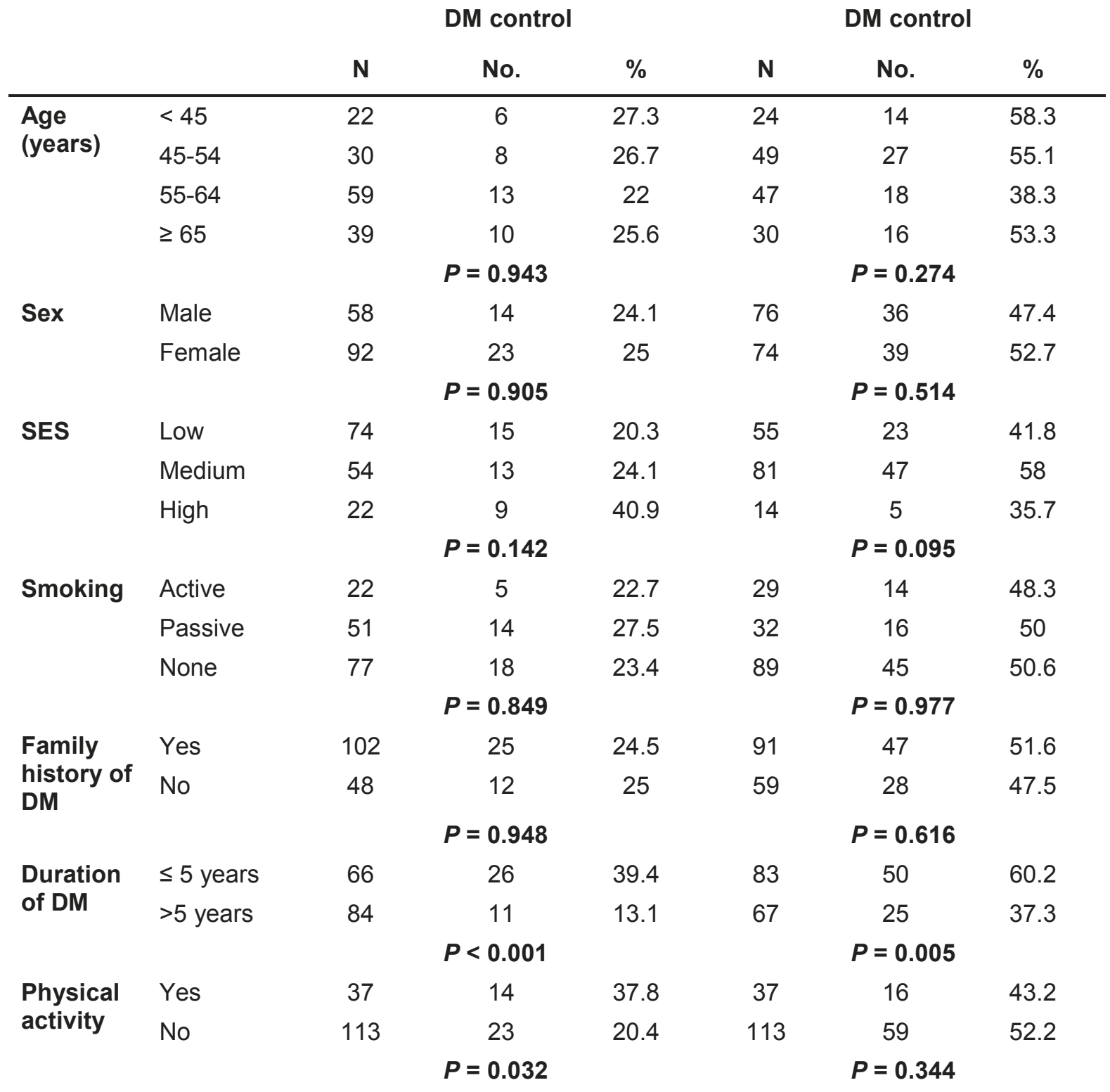

Note: All $p$ values of the above table were calculated by Chi-square test. 
Table 4 shows that half of the Brayati center sample had $\geq 3$ controlled risk factors compared with around one-quarter of the DM center sample $(P<0.001)$. Logistic regression analysis shows that being a patient in Brayati center $(\mathrm{OR}=3.1)$

Table 4: Distribution of the samples of the two centers by the number of controlled risk factors.

\begin{tabular}{|c|c|c|c|c|c|}
\hline \multirow{2}{*}{$\begin{array}{l}\text { No. of controlled } \\
\text { risk factors }\end{array}$} & \multicolumn{2}{|c|}{ Leila Qasim diabetic center } & \multicolumn{2}{|c|}{ Brayati family medicine center } & \multirow[t]{2}{*}{$P$ value } \\
\hline & No. & $\%$ & No. & $\%$ & \\
\hline Zero & 23 & 15.3 & 13 & 8.7 & \\
\hline One & 47 & 31.3 & 32 & 21.3 & \\
\hline Two & 42 & 28.0 & 30 & 20.0 & \\
\hline Three & 30 & 20.0 & 45 & 30.0 & -0.001 \\
\hline Four & 4 & 2.7 & 23 & 15.3 & \\
\hline \multirow[t]{2}{*}{ Five } & 4 & 2.7 & 7 & 4.7 & \\
\hline & 150 & 100.0 & 150 & 100.0 & \\
\hline
\end{tabular}

*By Chi-square test.

Table 5: SPSS output of logistic regression analysis between diabetes control as a dependent variable with several covariates.

\begin{tabular}{|c|c|c|c|c|}
\hline Variables & B & $P$ value & OR & $\begin{array}{l}95 \% \mathrm{Cl} \text { for OR } \\
\text { Lower - Upper }\end{array}$ \\
\hline Brayati family medicine center & 1.152 & $<0.001$ & 3.163 & $(1.822-5.491)$ \\
\hline \multicolumn{5}{|l|}{ Leila Qasim center (reference) } \\
\hline Obesity & & 0.171 & & \\
\hline Normal weight & -0.216 & 0.564 & 0.806 & $(0.387-1.679)$ \\
\hline Over-weight & 0.401 & 0.219 & 1.493 & $(0.788-2.831)$ \\
\hline \multicolumn{5}{|l|}{ Obese (reference) } \\
\hline DM duration ( $\leq 5$ years) & 1.127 & $<0.001$ & 3.085 & $(1.836-5.186)$ \\
\hline \multicolumn{5}{|l|}{ DM duration > 5 years (reference) } \\
\hline Controlled lipid & 0.942 & 0.004 & 2.564 & $(1.350-4.869)$ \\
\hline \multicolumn{5}{|l|}{ Uncontrolled lipid (reference) } \\
\hline Constant & -2.077 & $<0.001$ & 0.125 & \\
\hline
\end{tabular}




\section{Discussion}

Approximately $20-30 \%$ of patients visiting family practices suffer from T2DM, and they can be treated effectively at primary care settings to decline the substantial burden of diabetes-related complications. ${ }^{12}$ Access to primary care is universal, and the primary care physician is responsible for all routine follow-ups, including diabetic care. Few studies in developing countries including Iraq have explored the glycemic control at PHC and extents of adherence in the application of guidelines for diabetes management. This study was designed to compare the percent of glycemic control $(\mathrm{HbA} 1 \mathrm{c}<7)$ and diabetes-related comorbidities among patients of the $\mathrm{PHC}$ and specialized DM center. The stress is primarily on the family medicine center, rather than on the $\mathrm{PHC}$ because this center ensures that services are patient-centered and delivered by appropriately skilled physicians. The present study showed that the mean $\mathrm{HbA} 1 \mathrm{c}$ of diabetic patients of the Brayati family medicine center was significantly lower than the mean of patients at DM center $(7.21 \%, 8.28 \%$ respectively). Moreover, patients who reached $\mathrm{HbA} 1 \mathrm{c}<7$ are $50 \%$ at Brayati center compared to only $24.7 \%$ at DM center, a result which was higher than many previous studies. In Oman, a study revealed that only $9.6 \%$ and $35 \%$ of the patients reached optimal FBS and $\mathrm{HbA} 1 \mathrm{c}$ levels, respectively. The mean $\mathrm{HbA} 1 \mathrm{c}$ was significantly higher at $\mathrm{PHC} .^{13}$ This result was similar to that reported in Jordan where $34.9 \%$ of the study population had $\mathrm{HbA} 1 \mathrm{c}<7 \%$ and was associated significantly with a longer duration of the disease at the family medicine centers. ${ }^{14}$ However, choosing family medicine center may be the contributing factor to the rise of the rate of the glycemic control in the present study compared to Oman and Jordan studies that conducted mainly in PHC centers. In China, only $36.2 \%$ of the patients their $\mathrm{HbA} 1 \mathrm{c}<6.5 \%$ at $\mathrm{PHC}$ compared to those managed at tertiary. ${ }^{15}$ Both results were better than those reported in Malaysia, involving $\mathrm{PHC}$ centers and hospitals. In 49 general practice clinics involving 438 patients with type T2DM, only $20 \%$ achieved $\mathrm{HbA} 1 \mathrm{c}$ $<7 \%$, whereas just $11 \%$ had fasting blood glucose levels of $<6.7 \mathrm{mmol} / \mathrm{L}^{16}$ On the other hand, many previous studies in developed countries revealed results similar to the present study with a higher prevalence of $\mathrm{HbA} 1 \mathrm{c}<7$. In Canada, $51 \%$ of the population study had $\mathrm{HbA} 1 \mathrm{c} \geq 7 \%$ with mean $\mathrm{HbA} 1 \mathrm{c} 7.3 \%{ }^{17}$, and in Japan, a study showed that majority of diabetes patients who were treated by general practitioners had good glycemic control $(45 \%){ }^{18}$ Whereas, in Germany, about $65 \%$ of patients had reached $\mathrm{HbA} 1 \mathrm{c}<7 \%$. ${ }^{19}$ Although assumptions cannot be established by comparing studies performed with different design and patients population, the observed a higher prevalence of $\mathrm{HbA} 1 \mathrm{c}<7 \%$ in the present study compared to other developing countries agrees with clinical trials from developed countries. One reason could be that the majority of the doctors' at Brayatii center were certified family physicians who provide more attention and spend more time with T2DM patients. It has been advised that a good consultation and patient-doctor communication certainly can affect the quality of care. ${ }^{20}$ Dyslipidemia is a major risk factor for cardiovascular disease in diabetic patients, the mean of TG, T-C, and LDL-C were significantly lower in the Brayati center compared with DM center moreover, the percentage of patients that reached the target level of lipids were significantly higher in the Brayati center $(40.7 \%, 56.0 \%$, and $30.0 \%$, respectively) compared with DM center $(28.0 \%, 40.7 \%$, and $15.3 \%$, respectively). This is another good indicator that diabetes -related comorbidities can be effectively controlled by skilled physicians in well-organized primary care. The current results approximately similar to that of a Saudi Arabia study where only $17.4 \%$ of patients achieved TG target, $38.7 \%$ achieved the T-C target, and $45.2 \%$ 
achieved LDL-C target in PHC in Jeddah City. ${ }^{21}$ Diabetic microvascular and macrovascular complications have similar etiologic characteristics. Long-lasting hyperglycemia plays a major role in the initiation of diabetic vascular complications. Studies demonstrated strong evidence that these complications eliminated by optimal glycemic control, lipid profile and screening for microalbuminuria. ${ }^{22}$ The current study showed that half of the patients at Brayatti center succeeded optimal glycemic control adding to that the proportion of the patients which had $\geq 3$ controlled risk factors like lipids, BMI and BP were significantly higher (30\%) compared with $20 \%$ of the patients of the DM center. Glycemic control is an important indicator for quality of care, and clinical inertia may be one of the reasons why the level of $\mathrm{HbA1c}$ is worse than generally recommended. ${ }^{23}$ Clinical inertia requires conjunction of the patient with physician and health system. Many factors affect or affected by clinical inertia that in turn affect glycemic control and these are related to patient, physician, and health care system. Unusually a study revealed that patients whose treatment was initiated by a diabetologist experience have more clinical inertia than those treated at PHC center. ${ }^{24}$ The current study found no significant association between diabetes control with variables like age, sex, SES, smoking, as well as family history of DM, but there was a statistically significant association with duration of the disease, the less the duration of diabetes the more the percentage of control irrespective of the center. This finding is inconsistent with that of a study conducted in Hulu Langat district in Malaysia which showed that the four variables have an association with the outcome of glycemic control (age, duration of diabetes mellitus, drug utilization pattern and adherence). ${ }^{25}$ In order to identify the factors associated with good glycemic control among patients, four factors have been taken into consideration, the center, obesity, DM duration, and controlled lipid profile. Logistic regression analysis showed that being a patient treated in Brayati center, having the disease of less than five years and achieved target lipid profile were associated with better DM control. The duration of DM negatively affects the DM control because when the disease progresses, most patients require an increase in their drugs to maintain glycemic control, a result which was similar to the previous study. ${ }^{25}$ The same results regarding lipids have been obtained in another study among Turkish patients that showed a significant increase in the mean serum levels of TC, TG, LDL-C and decrease in HDL-C during the course of diabetes. ${ }^{26}$ The relative high control of diabetes in this study compared to previous studies could be explained by providing continuous care in a well-organized family medicine center. The current study focused on the family physician's role in diabetic care; however, supervision of glycemic control and screening for diabetes complication in all PHC centers should be improved. Misunderstandings among the population in developing countries that T2DM patients should only be treated by endocrinologist and obstacles external to physicians are still serious problems and should be improved by social media, skilled physicians and patient-doctor communication. Finally, additional research involving more PHC centers and focusing on glycemic inertia are strongly recommended. Patient's compliance with treatment and selecting one family medicine center might be the main limitations of the current study. It is worth to mention that Bryati center is the first family medicine center in Erbil which is well established, contrary to the other centers that face family medicine staff shortage. This may be one of the contributing factors to the inflation of the rate of diabetic control. On the other hand, this study achieved at least one of the goals that designed to explore diabetes management at PHC level in Erbil city and shows that delivery of diabetes care could 
be as effective as tertiary care level.

\section{Conclusion}

The T2DM can be effectively managed at $\mathrm{PHC}$, and good glycemic control can be achieved by a greater effort of the health care providers. Such finding focuses on the importance of providing organized care for diabetes patient in the primary care setting and can be a base for further studies to evaluate such care.

\section{Competing interests}

The author declares no competing interests.

\section{References}

1. International Diabetes Federation. IDF Diabetes Atlas. $6^{\text {th }}$ ed. Brussels: IDF; 2013. (Accessed November 1, 2015, at: http:// www.diabetesatlas.org/resources/how-tocite.html).

2. Whiting DR, Guariguata L, Weil C, Shaw J. IDF diabetes atlas: global estimates of the prevalence of diabetes for 2011 and 2030. Diabetes Res Clin Pract 2011; 94(3):311-21.

3. Krentz AJ, Bailey CJ. Type 2 diabetes in practice, $2^{\text {nd }}$ ed. London, UK: Royal Society of Medicine Press Ltd.; 2005.

4. Williams G, Pickup JC. The Handbook of Diabetes Paperback, $3^{\text {rd }}$ ed. Oxford: Blackwell Publishing Ltd; 2004.

5. American Diabetes Association. Diagnosis and Classification of Diabetes Mellitus. Diabetes Care 2014; 37(Supplement 1):S81-90.

6. Spann SJ, Nutting PA, Galliher JM, Peterson KA, Pavlik VN, Dickinson LM, et al. Management of type 2 diabetes in the primary care setting: a practice-based research network study. Ann Fam Med 2006; 4(1):23-31.

7. Goyder EC, McNally PG, Drucquer M, Spiers N, Botha JL. Shifting of care for diabetes from secondary to primary care, 1990-5: review of general practices. BMJ 1998; 316(7143):1505.

8. Ho M, Marger M, Beart J, Yip I, Shekelle P. Is the quality of diabetes care better in a diabetes clinic or in a general medicine clinic? Diabetes Care 1997; 20(4):472-5.

9. de Fine Olivarius N, Beck-Nielsen $H$, Andreasen $\mathrm{AH}$, Horder $\mathrm{M}$, Pedersen PA. Randomised controlled trial of structured personal care of type 2 diabetes mellitus. BMJ 2001; 27;323(7319):970.

10. Martin JC, Avant RF, Bowman MA, Bucholtz $\mathrm{JR}$, Dickinson JR, Evans $\mathrm{KL}$, et al. The future of family medicine: a collaborative project of the family medicine community. Ann Fam Med 2004; 2(suppl 1):S3-32.

11. Daniel WW. Biostatistics: A Foundation for
Analysis in the Health Sciences. $7^{\text {th }}$ ed. New York: John Wiley \& Sons Publishing Ltd; 1999.

12. Demirci $H$, Satman I, Çınar $Y$, Bilgel $N$. Essentials of Diabetes Care in Family Practice. In Diabetes Mellitus-Insights and Perspectives. Croatia: InTech Prepress, Novi Sad; 2013.

13. Al Balushi KA, Al-Haddabi M, Al-Zakwani I, Al Za'abi M. Glycemic control among patients with type 2 diabetes at a primary health care center in Oman. Prim Care Diabetes 2014; 8(3):239-43.

14. Khattab M, Khader YS, Al-Khawaldeh A, Ajlouni $\mathrm{K}$. Factors associated with poor glycemic control among patients with type 2 diabetes. J Diabetes Complication 2010; 24(2):84-9.

15. Bi Y, Zhu D, Cheng J, Zhu Y, Xu N, Cui S, et al. The status of glycemic control: A cross-sectional study of outpatients with type 2 diabetes mellitus across primary, secondary, and tertiary hospitals in the Jiangsu province of China. Clin Ther 2010; 32(5):973-83.

16. Ismail IS, Nazaimoon WW, Mohamad WW, Letchuman R, Singaraveloo M, Pendek R, et al. Socioedemographic determinants of glycaemic control in young diabetic patients in peninsular Malaysia. Diabetes Res Clin Pract 2000; 47(1):57 -69 .

17. Leiter LA, Berard L, Bowering CK, Cheng AY, Dawson KG, Ekoé JM, et al. Type 2 diabetes mellitus management in Canada: is it improving? Can J Diabetes 2013; 37(2):82-9.

18. Arai K, Takai M, Hirao K, Matsuba I, Matoba K, Takeda $\mathrm{H}$, et al. Present status of insulin therapy for type 2 diabetes treated by general practitioners and diabetes specialists in Japan: Third report of a cross-sectional survey of 15,652 patients. J Diabetes Investig 2012; 3(4):396-401.

19. Reisig $V$, Reitmeir $P$, Döring $A$, Rathmann $W$, Mielck A. Social inequalities and outcomes in type 2 diabetes in the German region of Augsburg. A cross-sectional survey. Int J Public Health 2007; 52(3):158-65.

20. Rhodes DR, McFarland KF, Finch WH, Johnson $A O$. Speaking and interruptions during primary care office visits. Fam Med 2001; 33(7):528-32.

21. Hhadija B, Alla HF, Mehad HF, Rajaa M, Eman A, Bahaa A, et al. Prevalence of dyslipidemia and its associated factors among employees of primary health care centers, Jeddah, Saudi Arabia. Int J Med Sci Public Health 2016; 5(5):947-51.

22. Stolar M. Glycemic control and complications in type 2 diabetes mellitus. Am J Med 2010; 123(3):S3-11.

23. Shah BR, Hux JE, Laupacis A, Zinman B, Van Walraven C. Clinical inertia in response to inadequate glycemic control. Diabetes Care 2005; 28(3):600-6.

24. Lang VB, Marković BB, Kranjčević K. Family physician clinical inertia in glycemic control among patients with type 2 diabetes. Med Sci 
Monit 2015; 21:403-11.

25. Ahmad NS, Islahudin F, Paraidathathu T. Factors associated with good glycemic control among patients with type 2 diabetes mellitus. J Diabetes Investig 2014; 5(5):563-9.

26. Ozder A. Lipid profile abnormalities seen in T2DM patients in primary healthcare in Turkey: a cross-sectional study. Lipids Health Dis 2014; 13(1):183. 